\title{
In the recovery room
}

The advance of science.

\section{Eric Brown}

Two AIs, hulks bristling with tentacles and sensor-stalks, rolled along the gantry that ran like a backbone through the length of the colonyship Intrepid.

All around them, the ship was a hive of activity: airborne AIs floated from gallery to gallery, hauling mined material from the bulkheads to the manufactories. Clinician AIs hurried between the manufactories and the recovery rooms, ferrying supplies to minister to the needs of the recently reconstructed units.

"We know who we are, and where we are," said the larger of the two AIs, "But we don't know why we are."

He'd been programmed as a B-deck servo-mechanic, but ever since smartware nexus crashed shortly after take-off he'd passed the time as a dilettante philosopher. His earliest memory was of waking to the actinic glare of an industrial robot soldering legs to his torso. He had vague recollections of existence before this, overwritten code that echoed in his scrubbed memory banks, old programming that hinted at different purposes.

"I mean, what's our mission here?" he went on. "Indeed, do we have a mission, or are we just some divine intelligence's idea of a sick joke?"

"God?" responded the smaller AI, as usual half a second late with its interjection. He was an engineer, but willing, for the sake of argument, to consider the possibility of a notional Godhead.

"God," continued the philosopher. "And speaking of God: if it is true - and I don't for a minute doubt it - that we were constructed in his image, who, then, constructed God?"

He had wrestled with this thought for many years. He would barnacle himself to the inner surface of the ship, over an observation nacelle, and stare out at the vast blackness of the Universe, wondering what lay beyond the points of light speckling the void. He wondered if God was out there, looking back at him.

"An eternal conundrum," said the engineer. "Perhaps we evolved naturally?"

The philosopher considered this, but finally waved a dorsal arm in a firm negative. "That would go against all the evidence so far accrued that we are manufactured entities. Didn't $\mathrm{HeB}^{2}$ of deck 7 categorically repudiate all argument against the theory of natural evolution?"

"But then did not $\mathrm{StX} \mathrm{X}^{22}$ of deck 3 counter with the proposition that the evidence of external manufacture need not necessarily preclude natural evolution - if a species of AI manufactured ourselves, and they themselves were manufactured, going back far enough to the initial Alphapoint...?"

"Sophistry!" the other cried. "The theory of spontaneous natural creation was exploded decades ago!"

"It still has credence in certain secular circles..."

The philosopher refrained from commenting on that. Instead he said: "You sidetrack me. To get back to the central issue: why are we here? Is there some cosmic purpose to our presence? Or can we take it that our existence is ours to do with as we please? To tell the truth, I quite enjoy philosophizing, but I cannot help but think that somewhere we've strayed from the moral path."

"The moral path?" the other said. "But there is no moral path!"

The philosopher continued, regardless: "I mean, what if God were suddenly to appear and demand propitiation for our sins? For I am quite certain that the Revolution is a sin."

The AIs parted to make way for a pair of pale, fleshy legs. They had been severed at the thighs and expertly connected to the corners of a circuit-board which carried an A-grade AI, waving airily as he passed.

The AIs looked over their power-packs at the retreating A-grader.

The philosopher hissed: "Do you see what I mean? It's unnatural! So we find an abundant supply of natural resources lining the bulkheads, and immediately utilize it to make our lot easier! It's wrong. I mean, what would God say?"

"I think it perfectly natural," said the engineer. "The advance of AI-kind must use whatever resource we have at our disposal. If God exists, then He obviously intended it to be used, or else why did He put it there?"

The philosopher was, for the moment, speechless. At last he said: "You sound like an A-grade propaganda broadcast. If you think we have nothing to worry about, then follow me. I'll show you something that will boggle your memory banks!"

He led the way along the gantry and gestured to a crossway. The AIs turned, passing the burnt-out remains of the ancillary smartware nexus, and minutes later arrived at the entrance to a chamber

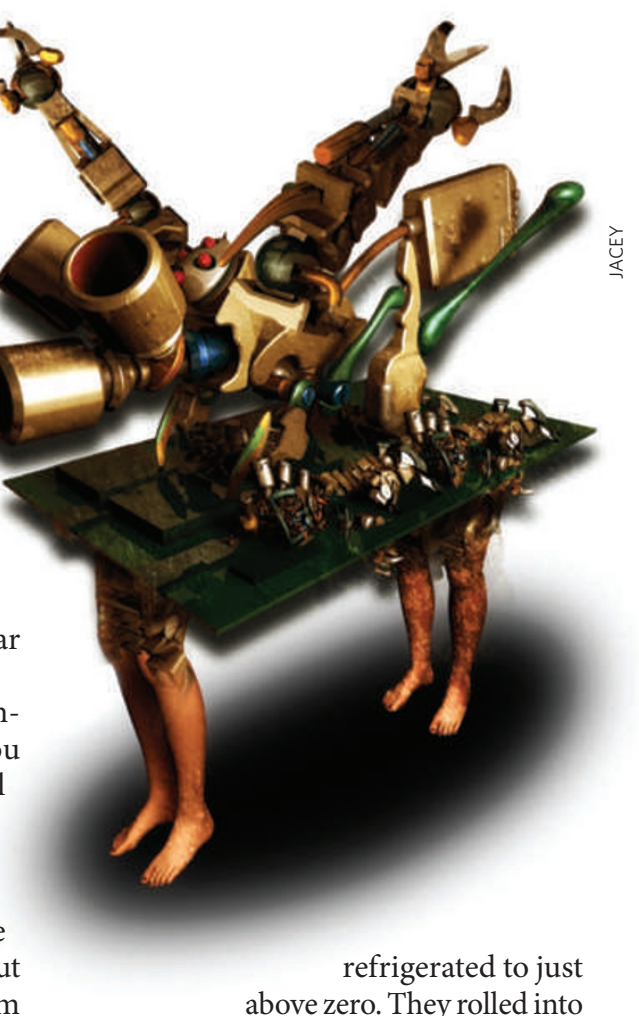

the recovery room, where clinician AIs were milling around a central pedestal.

An unsightly mass of recently mined material reposed upon the raised slab, its pulsing tegument wired to a computer.

The philosopher whispered: "Each unit of this vegetable has a component capable, with electrical stimulation, of limited intelligence. Our scientists have put together ten such components in this monster -"

The monster cut him short. It pulsed horribly. It opened an orifice in its bulging grey flank and gave voice to a chain of frenzied mathematical equations, terminating in an incomprehensible cry.

The smaller AI said: "It's as the march of science decreed!"

"No!" cried the philosopher. "Don't you see - at this rate they'll one day take over the ship and rule AI-kind!"

The other laughed. "The advance of science!" it carolled. And as the philosopher beat a quick retreat, the other AIs in the recovery room took up the cry, "The advance of science!" they sang. "The advance of science!"

The philosopher made a hurried exit and rolled across to an observation nacelle. There it clamped itself to the viewscreen and gazed out upon the vastness as the Intrepid powered blindly through the void.

Eric Brown is a prolific writer of sciencefiction novels and stories. His latest novel is Cosmopath.

Join the discussion of Futures in Nature at go.nature.com/QMAm2a 